\title{
Differential Modulation of Clock Speed by the Administration of Intermittent Versus Continuous Cocaine
}

\author{
Matthew S. Matell \\ University of Michigan Medical School
}

\author{
George R. King \\ Texas Christian University
}

\author{
Warren H. Meck \\ Duke University
}

\begin{abstract}
The roles that psychostimulant sensitization and tolerance play in temporal perception in the secondsto-minutes range were assessed in rats. Cocaine $(20 \mathrm{mg} / \mathrm{kg} /$ day $)$ was administered for 2 weeks either intermittently via daily injections (induces sensitization) or continuously via an osmotic minipump (induces tolerance). Interval timing was evaluated throughout administration and withdrawal. Injections of cocaine caused immediate, proportional, leftward shifts in peak times, indicating an increase in the speed of an internal clock. These shifts grew progressively larger with repeated administration, indicating that stimulant-induced increases in clock speed can be sensitized. Continuous cocaine administration produced no reliable effects. These results suggest that the mechanisms of sensitization may play a considerable role in drug-induced alterations of the perception of time.
\end{abstract}

Repeated intermittent administration of psychostimulants, such as cocaine, has been shown to elicit sensitization, or an augmented response to the effects of the drug, in a wide variety of behaviors, including the locomotor stimulating effects (Post \& Rose, 1976; Segal \& Mandell, 1974), lick speed (Badiani \& Stewart, 1999) and readiness to self-administer stimulants (Piazza, Deminiere, le Moal, \& Simon, 1990; Schenk \& Partridge, 1997). On the other hand, continuous administration of cocaine has been shown to induce tolerance to its behavioral and neurochemical effects (Chen \& Reith, 1993; King et al., 1994; King, Joyner, \& Ellinwood, 1994; King, Joyner, Lee, Kuhn, \& Ellinwood, 1992; King, Kuhn, \& Ellinwood, 1993; King, Xiong, Douglas, Lee, \& Ellinwood, 1999; King, Xiong, \& Ellinwood, 1997, 1999; King, Xue, Calvi, \& Ellinwood, 1995; Matell \& King, 1997; Reith, Benuck, \& Lajtha, 1987). Although the mechanisms underlying the development and maintenance of sensitization and tolerance are complex and depend on the dose, route, and schedule of administration (for reviews, see Hammer, Egilmez, \& Emmett-Oglesby, 1997; Kalivas, 1995; Kalivas \& Stewart, 1991; Post, Weiss, Fontana, \& Pert,

Matthew S. Matell, Department of Neurology, University of Michigan Medical School; George R. King, Department of Psychology, Texas Christian University; Warren H. Meck, Department of Psychological and Brain Sciences, Duke University.

A preliminary report of the work was presented at the annual meeting of the Society for Neuroscience (Matell, Meck, \& King, 1996). This research and manuscript preparation were supported, in part, by National Institutes of Health Grants F31 DA05838, F32 AG20957, 1R01-DA10468, 1R29DA08899, and MH544799.

Correspondence concerning this article should be addressed to Matthew S. Matell, who is now at the Department of Psychology, Villanova University, Tolentine Hall, 800 Lancaster Avenue, Villanova, PA 19085. E-mail: matthew.matell@villanova.edu
1992), changes in dopamine neurotransmission and functionality have been strongly implicated. As such, evaluating the effects of repeated administration of these drugs on other dopamine-related behaviors may extend the knowledge base regarding the neural and psychological mechanisms by which sensitization and tolerance operate, and may help in understanding of the role of such processes in drug abuse and addiction (Everitt \& Wolf, 2002; Kalivas \& Stewart, 1991; Kelley \& Berridge, 2002; Post et al., 1992; Robinson \& Berridge, 1993; White, 2002).

The ability of dopaminergic agents to distort the perception of time has been widely reported (Çevik, 2003a; Chiang et al., 2000; Drew, Fairhurst, Malapani, Horvitz, \& Balsam, 2003; Frederick \& Allen, 1996; Maricq \& Church, 1983; Maricq, Roberts, \& Church, 1981; Meck, 1983, 1986). For example, systemic administration of $1.5 \mathrm{mg} / \mathrm{kg}$ methamphetamine (MAP) produces an immediate horizontal and proportional leftward shift in a subject's psychophysical timing function, indicating a perceived increase in psychological time relative to physical time (Maricq et al., 1981). This leftward shift has been proposed to result from an increase in the speed of an internal clock used to perceive durations in the seconds-to-minutes range (Meck, 1983, 1996). In other words, MAP causes this internal clock to run faster than normal, such that a reward that normally occurs when the subject's internal clock reads $10 \mathrm{~s}$ seems to occur at a later time (e.g., when the internal clock reads $12 \mathrm{~s}$ ).

When MAP is given repeatedly, and the subject continues to receive training on the task, the leftward shift in peak time gradually renormalizes and eventually disappears (Meck, 1983, 1996). These data have been interpreted as a relearning of the criterion duration associated with the faster clock (i.e., the subject learns that reward now comes when its internal clock reads $12 \mathrm{~s}$, not $10 \mathrm{~s}$ ). When drug administration is discontinued (i.e., during withdrawal), a rebound effect occurs such that the timing functions 
are rightward shifted. This effect has also been interpreted as resulting from relearning (i.e., the clock is now running at its original rate, but the subject is still waiting for its clock to read $12 \mathrm{~s}$, not $10 \mathrm{~s}$ ).

In contrast to these learning explanations, within the context of the drug addiction literature, the renormalization and rebound effects are consistent with the development of tolerance to the drug's ability to increase clock speed. Because the development of clock-speed tolerance following this intermittent administration schedule is contrary to the sensitization of locomotor activity seen following a similar administration schedule of amphetamine (Tilson \& Rech, 1973), we evaluated the effects of two different schedules of cocaine administration (intermittent vs. continuous) on temporal estimation in the rat, using the tri-peak procedure (Matell \& Meck, 1999). These drug administration schedules have been previously shown to induce sensitization and tolerance to the locomotor effects of a challenge injection of cocaine following a 7-day withdrawal period (King et al., 1992; Reith et al., 1987)

\section{Method}

\section{Subjects}

Twenty-four naive Sprague-Dawley male rats weighing 200-300 g (Charles River Laboratories, Raleigh, NC) and approximately 4 months of age were used. Rats were housed in pairs in a 12-hr light-dark cycle, with lights on from 7 a.m. to 7 p.m. They were given continuous access to water and were maintained at $85 \%$ free-feeding weight by a daily ration of Purina Rat Chow given after the daily session.

\section{Apparatus}

All experimental data were obtained in eight standard operant chambers (Coulbourn Instruments, Allentown, PA). A pellet dispenser (Coulbourn Instruments, Allentown, PA) delivered 45-mg food pellets (Noyes Precision, Formula A; P. J. Noyes, Lancaster, NH) to a food cup located on the front wall. Two 4-cm retractable response levers (Coulbourn Instruments, Allentown, PA), located $2 \mathrm{~cm}$ from each side wall and one 4-cm nonretractable response lever (Coulbourn Instruments), were horizontally placed $2.5 \mathrm{~cm}$ above the grid floor across the front wall. A $2.5-\mathrm{cm}$ Sonalert (P. R. Mallory \& Co., Indianapolis, IN), calibrated to $93 \mathrm{~dB}$, was mounted in between the food cup and the center response lever. A 6-W houselight was located on the ceiling and was illuminated throughout the session. Each operant chamber was housed inside a wooden sound- and light-attenuating box, and was equipped with a $10-\mathrm{cm}$ ventilation fan and an eyepiece viewer for observation. An IBM-PC compatible computer attached to an electronic interface was used to control the experimental equipment and record the data.

\section{Drugs}

Cocaine hydrochloride (HCL; Sigma Chemical Co., St. Louis, MO) was dissolved in $0.9 \%$ (wt/vol) saline. For injections, the dose used was 20 $\mathrm{mg} / \mathrm{kg}$ intraperitoneally. For osmotic minipump delivery, the dose used was $60 \mathrm{mg} / \mathrm{ml}$, which delivered a total of $6.4 \mathrm{mg}$ of cocaine per dayapproximately the amount received by the injection group per day. The challenge injection was given at a dose of $15 \mathrm{mg} / \mathrm{kg}$ intraperitoneally. All doses were calculated as the salt.

\section{Minipump Preparation}

Alzet Osmotic pumps (Model 2 ML2; Alza Corp., Mountain View, CA) were filled with $2.5 \mathrm{ml}$ of either $60 \mathrm{mg} / \mathrm{ml}$ cocaine HCL or $0.9 \%$ saline.
The cocaine pumps were slightly modified by adding a microdialysis fiber to the output portal to minimize tissue necrosis from the cocaine (Joyner, King, Lee, \& Ellinwood, 1993). The infusion rate for cocaine was $5 \mu \mathrm{l} / \mathrm{hr}$, resulting in an overall dose of $20 \mathrm{mg} / \mathrm{kg}$ cocaine per day. The pumps were primed by warming in a water bath $\left(37^{\circ} \mathrm{C}\right)$ for $4 \mathrm{hr}$ before implantation.

\section{Surgery}

Rats were anesthetized briefly by inhalation with methoxyflurane (Metofane). They were shaved along the dorsal midline. A 2-cm incision was made with scissors, and a large subcutaneous pocket was made. The minipumps were inserted into the pocket with the delivery portal toward the head, and the wound was closed with surgical autoclips. Removal of the minipumps entailed a similar procedure, and the amount of residual cocaine solution was measured. No rat had more than $20 \%$ of the drug remaining in the minipump at the end of the treatment regimen.

\section{Pretraining (Sessions 1-6)}

All rats received six sessions of combined magazine and lever training. During these sessions, the left, middle, and right levers were primed in sequence on a fixed-ratio 1 schedule for 10 responses each. Autoshaping techniques (i.e., side levers were briefly retracted $1 \mathrm{~s}$ before free pellet delivery occurring once per min) were used to train the rat to respond for food. The direction in which the levers were primed (e.g., left lever, middle lever, and right lever) was based on the eventual direction of the 10-, 30-, and 90-s duration associated responses in the final procedure. This procedure was repeated until the rat pressed each lever 20 times or $60 \mathrm{~min}$ had passed.

\section{Fixed-Interval Training in Increasing Duration Order} (Sessions 7-12)

Trials began with the onset of a 93-dB tone. A 10-s fixed-interval (FI) was scheduled with either the right or the left response lever. The first response after $10 \mathrm{~s}$ was reinforced, and the sound stimulus was turned off After a 2-s delay, the sound stimulus was turned back on and a 30-s FI schedule was imposed on the middle lever. Following reinforcement of this lever press, the sound stimulus was again turned off for $2 \mathrm{~s}$. The sound was then turned on again, and a 90-s FI was scheduled on the remaining side lever. After reinforcement was earned for this lever, the tone was turned off, and a 55-s intertrial interval (ITI) was given, at which point the same schedule was repeated. This procedure was repeated for $95 \mathrm{~min}$. The short within-trial breaks between the increasing duration FIs were used to "move" the rat from one side of the operant chamber to the other during the three FI trials.

\section{FI Training in Random Order (Sessions 13-18)}

Sessions were identical to those described previously with the exception that on any particular trial, one FI duration was randomly selected, and the full 55-s ITI was instituted after every trial. In these trials, no indication was given to the rat regarding which duration $(10 \mathrm{~s}, 30 \mathrm{~s}$, or $90 \mathrm{~s})$ would be paired with reinforcement; therefore, the rat would generally initiate lever pressing on the 10-s duration lever. If this lever did not pay off, the rat would then switch to the 30-s duration lever. If again, responses to this lever were not reinforced, the rat would switch to the 90-s duration lever, for which responses on this lever would be reinforced after $90 \mathrm{~s}$ had elapsed since stimulus onset. All trial types were selected with equal probability.

\section{Peak-Interval Training (Sessions 19-32)}

These sessions were identical to those described earlier with the exception that a nonreinforced "probe" trial was added to the trial types ran- 
domly selected for each trial. These nonreinforced probe trials were variable in length $(270-330 \mathrm{~s})$.

\section{Drug Treatment and Testing Regimen (Sessions 33-54)}

Rats were randomly divided into three groups of 8 rats each. Each rat received an osmotic minipump containing either cocaine HCL (pump group) or saline (injection and control groups). Pump implantation immediately followed the last tri-peak training session. Each rat also received a subcutaneous injection of approximately $0.4 \mathrm{cc}$ of either saline (pump and control groups) or $20 \mathrm{mg} / \mathrm{kg}$ cocaine HCL (injection group), $2 \mathrm{hr}$ after pump implantation and immediately before each daily testing session. The injections were continued for a total of 14 days (13 testing sessions), at which point the pumps were removed. Rats were tested for an additional 6 days without injection. On Day 7 of withdrawal, a $15 \mathrm{mg} / \mathrm{kg}$ challenge injection of cocaine was given to all rats immediately before testing.

\section{Data Analysis: Mean Tri-Peak Functions}

The time of each lever press was recorded and placed into time bins (width $=10 \%$ of the criterion time for each lever). The data were then pooled over 3 days (with the exception of the final 4 drug days that were pooled together), plotted as a function of each lever's maximal response rate, and scaled so that the functions could be plotted over real time. Data were pooled over days because individual sessions did not provide sufficient data to produce smooth peak functions, thereby limiting our ability to characterize the rats' temporal estimates.

Statistical measures of the peak functions were derived by fitting each block of data with a Gaussian curve plus linear ramp function (SigmaPlot 2001; SPSS, Chicago, IL), with the mean and standard deviation of the fitted Gaussian function being used as the measure of the peak time and spread, respectively. Temporal control was verified by calculating the ratio of the fit of a straight line to the fit of a Gaussian function for each duration and block. If this ratio exceeded 0.8 , we concluded that the rat failed to temporally control its responses for that signal duration. One rat from the control group failed to show temporal control at any signal duration during the baseline period and was removed from the study. In addition, 8 of the remaining 23 rats (across all groups) failed to show temporal control for the long (90 s) duration during the baseline period, presumably because of the small number of probe trials used. Consequently, we report baseline data only from those rats that showed temporal control across all three durations $(n=15)$. Because the disruption of the 90 -s data was further compounded during the drug-administration phase of the experiment (see Drew et al., 2003 , for a report showing greater drug disruption on longer durations), we report only those data from the 10-s and 30-s response levers for the drug and withdrawal phases of the experiment $(n=23)$. The alpha level was set at $p<.05$ for all statistical analyses.

\section{Cocaine Effects}

A between-group, repeated-measure analysis of variance (ANOVA; $3 \times$ $8 \times 2$ ) using day (in blocks) and duration as within-subject variables was performed on the short and medium peak times, to determine whether the drug treatment and withdrawal had an effect on the time of peak responding. In a small subset of data (less than $2 \%$ distributed across all groups), the injection produced disruption to the rats' temporal control, and these data points were replaced with the rat's average from the three remaining administration blocks. Unfortunately, temporal control from the single challenge injection session was disrupted in all groups, thereby preventing a meaningful analysis. Therefore, these data are not presented.

\section{Results}

\section{Tri-Peak Baseline Data}

Rats responded on each lever as a function of time from the signal onset, as shown in Figure 1A. There were no significant
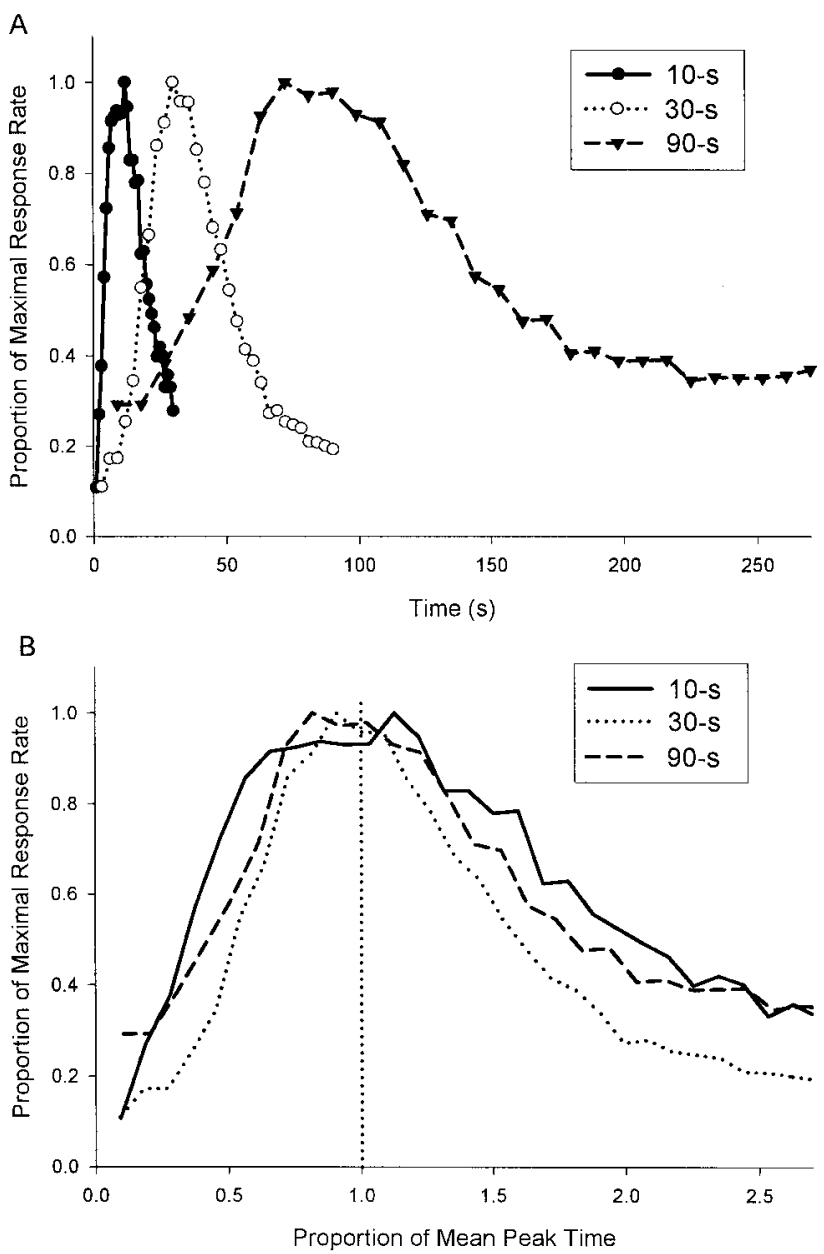

Figure 1. A: Mean lever-press responses from all rats on unreinforced probe trials from the predrug sessions (Sessions 27-32) plotted as a function of signal duration. Responding on each lever rises to a maximum near the time at which it would be primed for food delivery and drops nearly symmetrically thereafter. For presentation purposes, data have been normalized for maximum response rate across durations. B: Mean response rate plotted as a function of the obtained peak time in proportional time bins.

differences between groups or blocks on any measure (peak time, spread, and coefficient of variation $[\mathrm{CV}]$ ), so we combined these data to arrive at a single preadministration dataset.

Repeated measure ANOVAs evaluating CV from the preadministration dataset showed that there was a significant difference in $\mathrm{CV}$ as a function of stimulus duration, $F(2,28)=22.00$. These differences held across all three durations as assessed by Fisher's post hoc tests. These differences in $\mathrm{CV}$ can be readily seen when the response functions are normalized by the time of maximal responding, as illustrated in Figure 1B. Although the scalar property (Gibbon, 1977; Gibbon, Church, \& Meck, 1984) was violated in these data, this result was likely due to the effects of response competition (Hinson \& Staddon, 1978), rather than from a systematic breakdown of Weber's law (i.e., the response distributions do not get progressively sharper or wider with increasing duration). Specifically, as responding on the 30 -s lever will be sub- 
jected to response competition from both the 10-s lever and the 90 -s lever, this would lead to a smaller overall spread in responding on this lever in comparison to responding on the other two levers.

\section{Cocaine Effects}

The effect of cocaine administration on peak times over blocks is shown in Figure 2. The results of a repeated-measure, betweengroups ANOVA (Block $\times$ Duration) revealed a significant main effect for block, $F(6,140)=3.40$, as well as a Block $\times$ Group interaction, $F(12,140)=2.41$. Analyzing the effect for each group separately showed that the significant effect of block was due to changes in peak time in the injection group only, $F(6,42)=5.33$. In no case was there an effect of duration or a Duration $\times$ Block interaction. The previous analyses applied to spread and CV revealed no significant effects. As shown in Figure 2, the pattern of effects of intermittent injections of cocaine was an immediate leftward shift in peak time that increased in magnitude over the first two to three blocks of the administration period, which then reached a plateau by the final administration block. Post hoc analyses of group differences (least significant difference test) within each block are indicated by asterisks. Although we did not statistically analyze the 90 -s response data (because of a relatively small number of rats showing temporal control at this duration), the pattern of results from those rats that did reach criterion at this duration was similar (see Figures 2 and 3). In all cases, the maximal shift in peak times was on the order of $20 \%$ of the respective criterion duration. These leftward shifts in peak time result from a horizontal shift in the entire response distribution, as shown in Figure 3. In contrast, neither the pump nor the control groups showed any systematic shifts in peak times across the treatment or withdrawal periods. Terminating the administration regimen failed to produce a rebound effect that was significantly longer than the baseline peak time in any of the groups.

\section{Discussion}

The present experiment evaluated the effects of intermittent and chronic cocaine administration on timing and time perception in rats trained to perform on a tri-peak procedure with 10-s, 30-s, and 90 -s criterion durations. Schedules of cocaine administration previously shown to elicit either locomotor sensitization or tolerance (King et al., 1992; Reith et al., 1987) were used to investigate
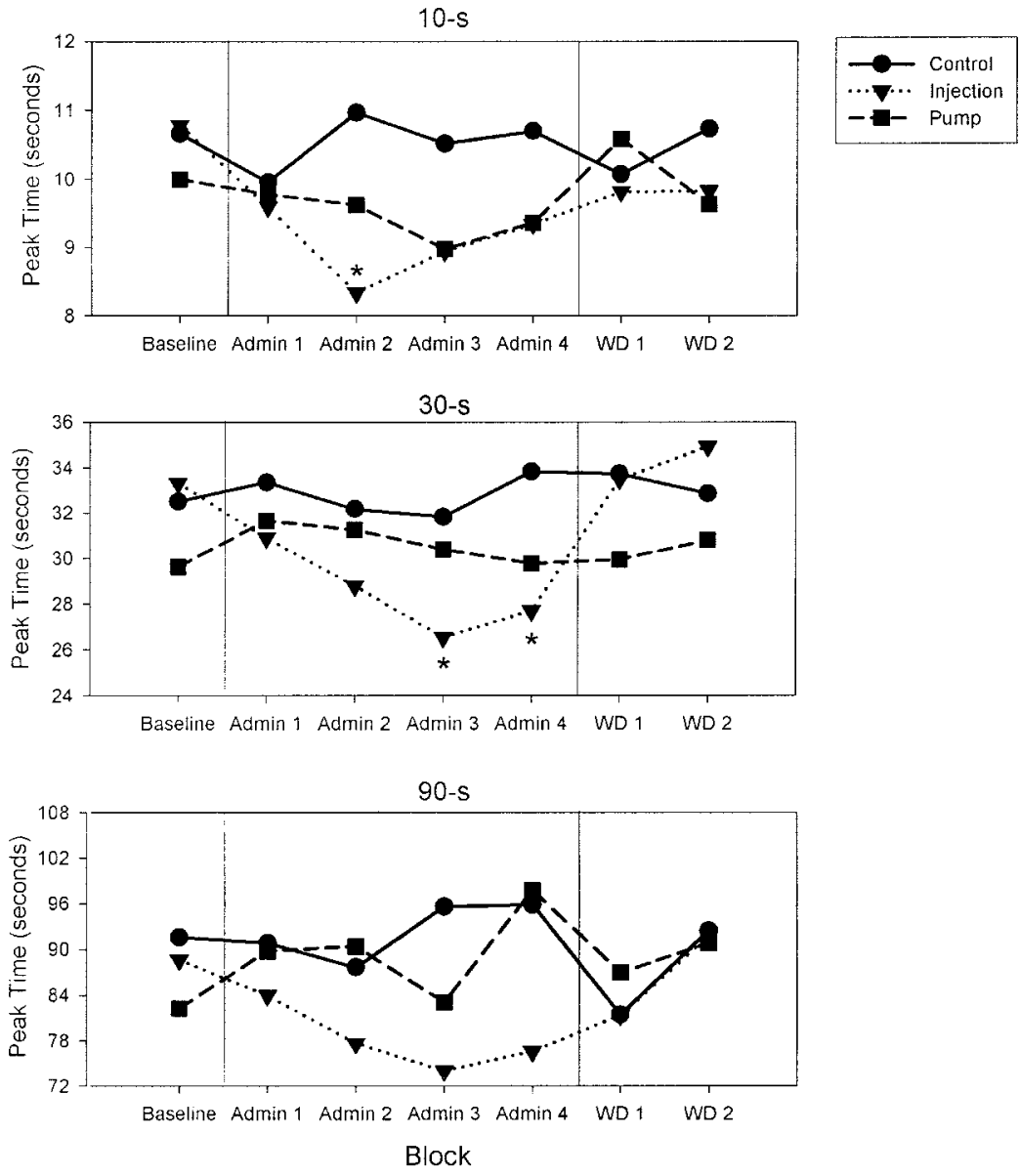

Figure 2. Mean peak times for each response lever plotted over blocks of three daily sessions separated by groups. Admin $=$ drug administration; WD $=$ withdrawal. 90 -s data were not statistically analyzed. $* p<.05$, compared with control. 


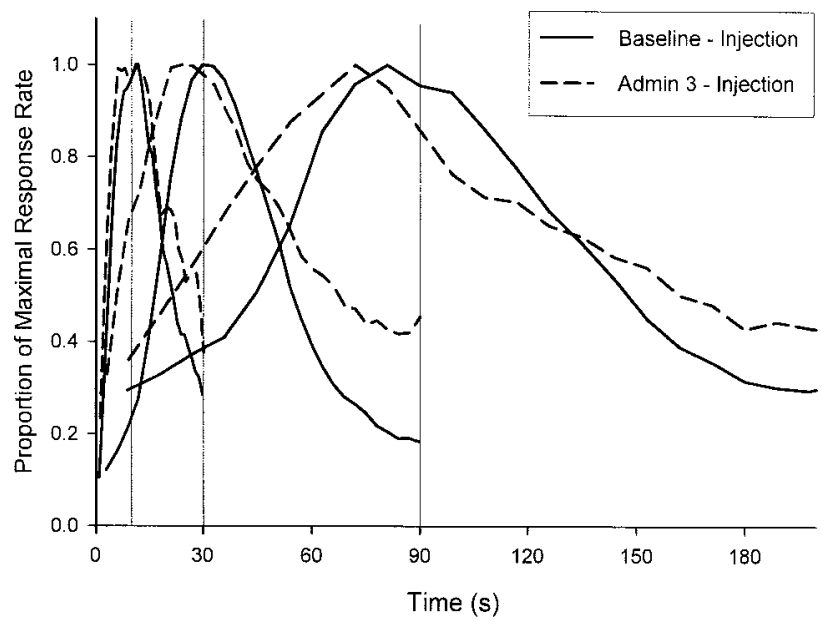

Figure 3. Mean lever-press responses from the baseline control data and drug administration (Admin) during Block 3 for the cocaine injection group. Vertical lines indicate the 10-, 30-, and 90-s fixed intervals.

whether cocaine-induced alterations in temporal perception would be modulated in a similar manner.

\section{Acute Cocaine Effects}

The horizontal and proportional leftward shifts seen after an acute injection of $20 \mathrm{mg} / \mathrm{kg}$ cocaine are similar to the leftward shifts observed after administration of the indirect dopaminergic agonist MAP (Meck, 1996). These results suggest that cocaine, like MAP, increases clock speed, further supporting the hypothesis that dopamine modulates the speed of an internal clock used to time durations in the seconds-to-minutes range (Buhusi \& Meck, 2002; Çevik, 2003b; Drew et al., 2003; Gibbon, 1977; Gibbon et al., 1984; Matell \& Meck, 2000, in press).

\section{Cocaine Effects Over Days}

Daily injections of cocaine produced a pattern of increasing leftward shifts in peak times that reached a plateau after 2 weeks of administration (see Figure 2). The current data indicate that the clock-speed enhancing effects of cocaine become sensitized with a similar schedule and trajectory as that observed in locomotor activity (Post \& Rose, 1976). Interestingly, the magnitude of sensitization reported here (i.e., the difference between the leftward shift from Block 1 to Block 3) was at least as large as the initial leftward shift, indicating that clock-speed sensitization can contribute significantly to drug-induced alterations in timing and time perception.

In contrast to the progressively growing shift in peak times resulting from daily injections, no effect was seen following chronic infusion of cocaine. Although we were unable to accurately assess the final effect of the chronic infusion because of the substantial disruption in timing found across all groups during the single challenge injection session, the lack of a tolerance-like effect during the treatment and withdrawal phases suggests that any alterations induced by the chronic infusion were subtle. The reasons for the differing effect size between injection and pump groups are not clear. However, recent data suggest that induction of tolerance may depend on the duration of time that cocaine is in the body (e.g., greater than $18 \mathrm{hr}$ of exposure appears necessary for the formation of tolerance to cocaine's locomotor effects (King, 1999). As such, the limited exposure to the behavioral task in the current experiment (i.e., $90 \mathrm{~min}$ per day) may have played an important role.

The current cocaine data are in contrast to the renormalization of peak times reported following repeated MAP administration (Meck, 1983, 1996). We also failed to observe a rebound in peak times following the cessation of cocaine administration. This renormalization/rebound effect had been explained as indicative of the subject relearning the relation between a specific internal clock reading and the delivery of reward (Meck, 1983, 1996). As the presently used schedule of drug administration and training should have provided ample opportunity to relearn this relationship (i.e., there were twice as many sessions here as in the MAP study), the current data suggest that the mechanisms contributing to the induction of clock-speed sensitization may interfere with the ability to modify temporal memories.

An alternative possibility is that the renormalization/rebound effect (Meck, 1983, 1996) does not result from the storage of new and modified temporal memories that offset changes in clock speed, but rather from a readjustment of clock speed itself (i.e., clock-speed tolerance). As such, it may be that seemingly minor differences in administration schedules between the two studies (i.e., pseudorandom daily injections of saline or MAP and temporal training only following MAP injections vs. daily injections of cocaine) may have led to the development of clock-speed tolerance versus clock-speed sensitization, respectively. The different patterns of clock-speed shifts between these studies may have also resulted from the different actions these drugs have on the brain both acutely and following long-term administration (see White \& Kalivas, 1998).

The time course of the drug effects observed here (i.e., during the administration period) appear more closely associated with the transient "initiation" phase of locomotor sensitization rather than the "expression" phase, which has been defined as the "long-term" consequences maintained during drug withdrawal (Pierce \& Kalivas, 1997). Interestingly, most of the anatomical changes found to underlie locomotor sensitization (which use virtually identical schedules of drug administration to those used here) are found within the ventral tegmental area (VTA; see Kalivas, 1995; White, $\mathrm{Hu}$, Zhang, \& Wolf, 1995, for reviews), whereas the substantia nigra pars compacta (SNPC; Meck, 2003) and the striatum (Matell, Meck, \& Nicolelis, 2003; Meck, 2003; Neil \& Herndon, 1978), but not the VTA (Meck, 2003), have been implicated in timing. As such, the SNPC and striatum may also be affected during the initiation phase - at least with rats being trained in an intervaltiming task. Such results suggest that the anatomical locations and mechanisms of sensitization and tolerance could potentially be intertwined with the behaviors that the subject is expressing during the initial drug administration.

In summary, we have shown that the systemic administration of cocaine can produce an increase in the speed of an internal clock used to time durations in the seconds-to-minutes range. Furthermore, repeated daily injections of cocaine lead to an augmentation of these clock-speed increases. While it is presently unclear whether alterations in temporal perception contribute to the use or abuse of psychostimulants, the current results showing reliable 
changes in timing as a result of a sensitizing schedule of cocaine administration suggest that further investigations of drug-induced alterations in timing and time perception are warranted.

\section{References}

Badiani, A., \& Stewart, J. (1999). Long-lasting sensitization to the accelerating effects of amphetamine on the speed of an internal clock. Behavioural Brain Research, 100, 217-223.

Buhusi, C. V., \& Meck, W. H. (2002). Differential effects of methamphetamine and haloperidol on the control of an internal clock. Behavioral Neuroscience, 116, 291-297.

Çevik, M. Ö. (2003a). Effects of methamphetamine on duration discrimination. Behavioral Neuroscience, 117, 774-784.

Çevik, M. Ö. (2003b). Neurogenomics of interval timing. In W. H. Meck (Ed.), Functional and neural mechanisms of interval timing (pp. 297316). Boca Raton, FL: CRC Press.

Chen, N. H., \& Reith, M. E. (1993). Dopamine and serotonin releaseregulating autoreceptor sensitivity in A9/A10 cell body and terminal areas after withdrawal of rats from continuous infusion of cocaine. Journal of Pharmacology and Experimental Therapeutics, 267, 14451453.

Chiang, T. J., Al Ruwaitea, A. S., Mobini, S., Ho, M. Y., Bradshaw, C. M., $\&$ Szabadi, E. (2000). The effect of d-amphetamine on performance on two operant timing schedules. Psychopharmacology (Berlin), 150, 170184.

Drew, M. R., Fairhurst, S., Malapani, C., Horvitz, J. C., \& Balsam, P. D. (2003). Effects of dopamine antagonists on the timing of two intervals. Pharmacology Biochemistry and Behavior, 75(1), 9-15.

Everitt, B. J., \& Wolf, M. E. (2002). Psychomotor stimulant addiction: A neural systems perspective. Journal of Neuroscience, 22, 3312-3320.

Frederick, D. L., \& Allen, J. D. (1996). Effects of selective dopamine D1and D2-agonists and antagonists on timing performance in rats. Pharmacology Biochemistry and Behavior, 53, 759-764.

Gibbon, J. (1977). Scalar expectancy theory and Weber's Law in animal timing. Psychological Review, 84, 279-325.

Gibbon, J., Church, R. M., \& Meck, W. H. (1984). Scalar timing in memory. In J. Gibbon \& L. Allen (Eds.), Annals of the New York Academy of Sciences: Vol. 423. Timing and time perception (pp. 52-77). New York: New York Academy of Sciences.

Hammer, R. P., Jr., Egilmez, Y., \& Emmett-Oglesby, M. W. (1997). Neural mechanisms of tolerance to the effects of cocaine. Behavioural Brain Research, 84, 225-239.

Hinson, J. M., \& Staddon, J. E. (1978, October 27). Behavioral competition: A mechanism for schedule interactions. Science, 202, 432-434.

Joyner, C., King, G., Lee, T. H., \& Ellinwood, E. H., Jr. (1993). Technique for the continuous infusion of high doses of cocaine by osmotic minipump. Pharmacology Biochemistry and Behavior, 44, 971-973.

Kalivas, P. W. (1995). Interactions between dopamine and excitatory amino acids in behavioral sensitization to psychostimulants. Drug \& Alcohol Dependence, 37, 95-100.

Kalivas, P. W., \& Stewart, J. (1991). Dopamine transmission in the initiation and expression of drug- and stress-induced sensitization of motor activity. Brain Research Reviews, 16, 223-244.

Kelley, A. E., \& Berridge, K. C. (2002). The neuroscience of natural rewards: Relevance to addictive drugs. Journal of Neuroscience, 22, 3306-3311.

King, G.R. (1999). [Effects of daily cocaine duration on the induction of tolerance]. Unpublished raw data.

King, G. R., Ellinwood, E. H., Jr., Silvia, C., Joyner, C. M., Xue, Z., Caron, M. G., \& Lee, T. H. (1994). Withdrawal from continuous or intermittent cocaine administration: Changes in D2 receptor function. Journal of Pharmacology and Experimental Therapeutics, 269, 743-749.

King, G. R., Joyner, C. M., \& Ellinwood, E. H., Jr. (1994). 5-HT3 receptor modulation of behavior during withdrawal from continuous or intermittent cocaine. Pharmacology Biochemistry and Behavior, 47, 399-407.

King, G. R., Joyner, C., Lee, T., Kuhn, C., \& Ellinwood, E. H., Jr. (1992). Intermittent and continuous cocaine administration: Residual behavioral states during withdrawal. Pharmacology Biochemistry and Behavior, 43, 243-248.

King, G. R., Kuhn, C., \& Ellinwood, E. H., Jr. (1993). Dopamine efflux during withdrawal from continuous or intermittent cocaine. Psychopharmacology (Berlin), 111, 179-184.

King, G. R., Xiong, Z., Douglas, S., Lee, T. H., \& Ellinwood, E. H. (1999). The effects of continuous cocaine dose on the induction of behavioral tolerance and dopamine autoreceptor function. European Journal of Pharmacology, 376, 207-215.

King, G. R., Xiong, Z., \& Ellinwood, E. H., Jr. (1997). Blockade of cocaine sensitization and tolerance by the co-administration of ondansetron, a 5-HT3 receptor antagonist, and cocaine. Psychopharmacology (Berlin), 130, 159-165.

King, G. R., Xiong, Z., \& Ellinwood, E. H., Jr. (1999). Withdrawal from continuous cocaine administration: Time dependent changes in accumbens 5-HT3 receptor function and behavioral tolerance. Psychopharmacology (Berlin), 142, 352-359.

King, G. R., Xue, Z., Calvi, C., \& Ellinwood, E. H., Jr. (1995). 5-HT3 agonist-induced dopamine overflow during withdrawal from continuous or intermittent cocaine administration. Psychopharmacology (Berlin), $117,458-465$.

Maricq, A. V., \& Church, R. M. (1983). The differential effects of haloperidol and methamphetamine on time estimation in the rat. Psychopharmacology (Berlin), 79, 10-15.

Maricq, A. V., Roberts, S., \& Church, R. M. (1981). Methamphetamine and time estimation. Journal of Experimental Psychology: Animal Behavior Processes, 7, 18-30.

Matell, M. S., \& King, G. R. (1997). 5-HT3 receptor mediated dopamine release in the nucleus accumbens during withdrawal from continuous cocaine. Psychopharmacology (Berlin), 130, 242-248.

Matell, M. S., \& Meck, W. H. (1999). Reinforcement-induced within-trial resetting of an internal clock. Behavioural Processes, 45, 159-172.

Matell, M. S., \& Meck, W. H. (2000). Neuropsychological mechanisms of interval timing behavior. Bioessays, 22, 94-103.

Matell, M. S., \& Meck, W. H. (in press). Cortico-striatal circuits and interval timing: Coincidence-detection of oscillatory processes. Cognitive Brain Research.

Matell, M. S., Meck, W. H., \& King, G. R. (1996). Changes in rescaling temporal responding on the tri-peak procedure after modulation of cocaine reactivity. Society for Neuroscience Abstracts, 22, 1130.

Matell, M. S., Meck, W. H., \& Nicolelis, M. A. L. (2003). Interval timing and the encoding of signal duration by ensembles of cortical and striatal neurons. Behavioral Neuroscience, 117, 760-773.

Meck, W. H. (1983). Selective adjustment of the speed of internal clock and memory processes. Journal of Experimental Psychology: Animal Behavior Processes, 9, 171-201.

Meck, W. H. (1986). Affinity for the dopamine D2 receptor predicts neuroleptic potency in decreasing the speed of an internal clock. Pharmacology Biochemistry and Behavior, 25, 1185-1189.

Meck, W. H. (1996). Neuropharmacology of timing and time perception. Cognitive Brain Research, 3, 227-242.

Meck, W. H. (2003). Neuroanatomical localization of an internal clock: A functional link between mesocortical, mesolimbic, and nigrostriatal dopaminergic systems. Manuscript submitted for publication.

Neil, D. B., \& Herndon, J. G., Jr. (1978). Anatomical specificity within rat striatum for the dopaminergic modulation of DRL responding and activity. Brain Research, 153, 529-538.

Piazza, P. V., Deminiere, J. M., le Moal, M., \& Simon, H. (1990). Stress- 
and pharmacologically-induced behavioral sensitization increases vulnerability to acquisition of amphetamine self-administration. Brain Research, 514, 22-26.

Pierce, R. C., \& Kalivas, P. W. (1997). A circuitry model of the expression of behavioral sensitization to amphetamine-like psychostimulants. Brain Research Reviews, 25(2), 192-216.

Post, R. M., \& Rose, H. (1976, April 22). Increasing effects of repetitive cocaine administration in the rat. Nature, 260, 731-732.

Post, R. M., Weiss, S. R., Fontana, D., \& Pert, A. (1992). Conditioned sensitization to the psychomotor stimulant cocaine. In P. W. Kalivas \& H. H. Samson (Eds.), Annals of the New York Academy of Sciences: Vol. 654. The neurobiology of drug and alcohol addiction. (pp. 386-399). New York: New York Academy of Sciences.

Reith, M. E., Benuck, M., \& Lajtha, A. (1987). Cocaine disposition in the brain after continuous or intermittent treatment and locomotor stimulation in mice. Journal of Pharmacology and Experimental Therapeutics, 243, 281-287.

Robinson, T. E., \& Berridge, K. C. (1993). The neural basis of drug craving: An incentive-sensitization theory of addiction. Brain Research Review, 18, 247-291.

Schenk, S., \& Partridge, B. (1997). Sensitization and tolerance in psycho- stimulant self-administration. Pharmacology Biochemistry and Behavior, 57(3), 543-550.

Segal, D. S., \& Mandell, A. J. (1974). Long-term administration of damphetamine: progressive augmentation of motor activity and stereotypy. Pharmacology Biochemistry and Behavior, 2, 249-255.

Tilson, H. A., \& Rech, R. H. (1973). Conditioned drug effects and absence of tolerance to d-amphetamine induced motor activity. Pharmacology Biochemistry and Behavior, 1, 149-153.

White, F. J. (2002). A behavioral/systems approach to the neuroscience of drug addiction. Journal of Neuroscience, 22, 3303-3305.

White, F. J., Hu, X. T., Zhang, X. F., \& Wolf, M. E. (1995). Repeated administration of cocaine or amphetamine alters neuronal responses to glutamate in the mesoaccumbens dopamine system. Journal of Pharmacology and Experimental Therapeutics, 273, 445-454.

White, F. J., \& Kalivas, P. W. (1998). Neuroadaptations involved in amphetamine and cocaine addiction. Drug and Alcohol Dependence, 51 141-153.

Received March 18, 2003

Revision received August 4, 2003

Accepted August 11, 2003 